\title{
TAHSP:-
}

The Internet Joutnal of Allied Health Sciences and Practice

A Peer Reviewed Publication of the College of Health Care Sciences at Nova Southeastern University

Dedicated to allied health professional practice and education

http://ijahsp.nova.edu Vol. 12 No. 1 ISSN 1540-580X

\section{Electronic Practical Skills Assessments in the Health Professions: A Review}

\author{
Suzanne J Snodgrass, BS(PT), MMedSc(Physio), PhD ${ }^{1}$ \\ Samantha E Ashby, DipCOT, BSc(Hons), Cert(Teaching \& Learning), MAppSci(OT), PhD² \\ Laura Onyango, BSc, $\mathrm{PhD}^{3}$ \\ Trevor Russell, BPhty, $\mathrm{PhD}^{4}$ \\ Darren A Rivett, BAppSc(Phty), GradDip(ManipTher), MAppSc(ManipPhty), PhD 5
}

1. Senior Lecturer, Physiotherapy, School of Health Sciences, The University of Newcastle, Newcastle, NSW Australia

2. Lecturer, Occupational Therapy, School of Health Sciences, The University of Newcastle, Newcastle, NSW Australia

3. Research Associate, School of Health Sciences, The University of Newcastle, Newcastle, NSW Australia

4. Associate Professor, Division of Physiotherapy, School of Health and Rehabilitation Sciences, The University of Queensland, St Lucia, QLD Australia

5. Professor and Head, School of Health Sciences, The University of Newcastle, Newcastle, NSW Australia

Australia

CITATION: Snodgrass SJ, Ashby SE, Onyango L, Russell T, Rivett DA. Electronic Practical Skills Assessments in the Health Professions. The Internet Journal of Allied Health Sciences and Practice. Jan 2014. Volume 12 Number 1.

\begin{abstract}
Objective Structured Clinical Examinations (OSCEs) evaluate the practical skills of students training in the health professions. OSCEs have several limitations, including a large administrative burden, potential inaccuracies when transferring student scores from paper to electronic mediums, and difficulties providing individualised student feedback. The "eOSCE," an electronic version of the traditional paper-based OSCE, potentially addresses these issues. In the eOSCE, examiners use electronic means (e.g. computer, personal digital assistant) to record student scores and comments about their performance, and the system provides students with individualised feedback. The literature from 12 databases was searched to identify articles discussing the use of electronic methods for practical skills assessment, focussing on health professions. Thirteen articles described the evaluation of health students' practical skills using electronic means. This review discusses the types of electronic methods used for practical skills assessments and the advantages and disadvantages of the types of eOSCEs compared to traditional paper-based formats.

\section{INTRODUCTION}

Assessments and evaluations are integral components in the teaching-learning process. They are regarded as essential in evaluating the progress of student learning as well as the effectiveness of the teaching process. ${ }^{1}$ Assessments not only evaluate the success of the student in learning and the educator in teaching but also the relevance of the course being taught and impact on the reputation of the educational institution. In learning, assessments play a role in the evaluation of a myriad of student skills in the formative and summative learning processes. Assessments can be administered using a wide array of methodologies, from paper-versions and oral examinations, to digital and electronic modes of evaluation. The evaluation of practical skills is essential in courses and professions that require the recall and practical application of knowledge and skills. Objective Structured Clinical Examinations (OSCEs) were developed for this purpose and were first utilised to evaluate the competence and practical clinical skills of medical students in their final year of study. 2,3 In OSCEs, examiners evaluate the practical skills of students as they perform a range of clinical skills and procedures across multiple skills stations with different clinical scenarios.
\end{abstract}

Originally designed by Harden in the 1970s, OSCEs were found to provide a more comprehensive evaluation of the clinical skills of medical students than the previous essay writing mode as the students transitioned from the stage of simply possessing

(c) The Internet Journal of Allied Health Sciences and Practice, 2014 
clinical knowledge to applying it in clinical settings.3,4 These authors argued that OSCEs enabled educators to evaluate large student cohorts and examine a broad range of practical skills within a reasonable time frame and with positive benefits and outcomes. Since then, several adaptations of the OSCE have been employed successfully across diverse fields of healthcare, including nursing, allopathic and osteopathic physicians, pharmacy, chiropractic, physical and occupational therapy, and dentistry and radiography, with reported benefits for students' learning of practical skills. ${ }^{5-9}$

Despite its reported benefits, the OSCE has several shortcomings which adversely affect its reliability and content validity. OSCEs which are administered with pen and paper have been reported as being not only tedious and time consuming in their development and administration but also prone to error as the results are transferred from paper to digital medium or educator to educator before reaching the student.10,11 In addition, there have been reports of student anxiety and dissatisfaction with feedback and with other aspects of the traditional OSCE, such as poor time management during the examination and concerns about equality of examination conditions. ${ }^{12}$ In response to this, adaptations of the OSCE using computerised or electronic marking systems have been developed. However, there is debate whether these adaptations are superior to the traditional paper-based OSCE. This review will discuss the types of electronic OSCEs (or eOSCEs) reported in the literature for assessing students' practical skills and their reported advantages and disadvantages.

\section{METHODS}

The purpose of this literature review was to explore the modes of electronic assessment used for the evaluation of practical skills in the healthcare professions. The main focus of the literature search was to retrieve all articles relevant to the use of the electronic assessment in the training of healthcare professionals, where practical skills formed a major component of the assessments. In July 2011, a search of the literature was conducted using the following terms: "OSCE," "electronic OSCE'leOSCE," "web OSCE," "electronic clinical assessments," "PDAs in practical assessment," "computerised clinical assessments," "computer-based OSCE," "mobile OSCE," "mOSCE," and "mobile technology in clinical assessment." The following databases were included in the search: PEDro, CINAHL, MEDLINE, AMED, CIRRIE, ScienceDirect, British Education Index, EBSCO Megafile Premier, Observatory on Borderless Higher Education, Psyclnfo, the Wiley Online Library and Google Scholar. All available years in each database were included in the search. In addition, hand-searching of the reference lists of retrieved articles was undertaken. Articles were included if they described the use of an electronic means to evaluate the practical or clinical skills of health professional students. Articles that described the use of electronic devices for information retrieval or other learning tasks were excluded.

\section{RESULTS}

Thirteen articles described the evaluation of health students' practical skills using electronic devices. These are summarised in Table 1.

Table 1. Types of Electronic Assessment (e-assessment) Reported in the Literature for the Evaluation of Students' PreProfessional Practical Skills in the Health Professions

\begin{tabular}{|c|c|c|}
\hline Type & Description & Authors \\
\hline $\begin{array}{l}\text { Fixed computer (desktop or } \\
\text { laptop) }\end{array}$ & $\begin{array}{l}\text { Students respond about scenarios portrayed or described on a } \\
\text { computer in the university setting }\end{array}$ & $\begin{array}{l}\text { Crisp }{ }^{16} \\
\text { Holyfield, et al. }{ }^{12} \\
\text { Nackman, et al. }{ }^{15} \\
\text { Palarm }{ }^{14}\end{array}$ \\
\hline PDAs & $\begin{array}{l}\text { Assessors use a PDA to record student marks and feedback in } \\
\text { an OSCE in the university or clinical setting }\end{array}$ & $\begin{array}{l}\text { Dearnley, et al. }{ }^{22} \\
\text { Kneebone }{ }^{20} \\
\text { Schmidts }{ }^{19} \\
\text { Torre, et al. }{ }^{23} \\
\text { Treadwell }{ }^{21}\end{array}$ \\
\hline Video & $\begin{array}{l}\text { Assessors evaluate student performance from a video in the } \\
\text { university setting }\end{array}$ & $\begin{array}{l}\text { Sturpe, et al. }{ }^{18} \\
\text { Vivekananda-Schimdt, et al. }{ }^{17}\end{array}$ \\
\hline Digital pen technology & $\begin{array}{l}\text { Assessors use a digital pen and special paper to record student } \\
\text { marks and feedback in an OSCE in the university } \\
\text { setting }\end{array}$ & van Hell, et al. ${ }^{24}$ \\
\hline Electromagnetic tracking & $\begin{array}{l}\text { Assessment consists of task performance of specific hand } \\
\text { movements recorded using electromagnetic } \\
\text { tracking }\end{array}$ & Yamaguchi, et al. ${ }^{25}$ \\
\hline
\end{tabular}

PDAs = personal digital assistants; OSCE = objective structured clinical examination

A much larger number of studies described the use of hand-held devices for information retrieval by students and the use of computers in assessments not related to practical skills. A range of methodologies and technologies were described as being 
used in the assessment of practical skills. The shift from traditional paper and pen OSCEs to computerised or digitised alternatives has become increasingly common in recent years. ${ }^{13}$ The range of devices utilised to administer, capture, evaluate, score, and report students' performance included desktop and laptop computers, audio and video recorders, personal digital assistants (PDAs) and other web-enabled mobile technologies, digital pen technology, and even electromagnetic motion-tracking systems. ${ }^{12,14-25}$ Table 1 summarises the types of electronic methods used to assess students' practical skills in the health professions that are reported in the literature.

\section{DISCUSSION}

\section{Technology in Education and Assessment}

Since the advent of the personal computer (PC), nearly all areas of industry have embraced the use of computerised technology because of its multi-faceted functions: data collection and analysis, storage, organisation, and information creation. Similarly, in the education sector, the use of computers and their associated applications has had a profound impact; many educational methods now utilise and integrate computer-based applications into the classroom and assessment to improve learning. Indeed, many educational institutions and learning programs adopt computerised technology to administer programs and curricula, thereby revolutionising how educators teach and potentially increasing the efficiency and effectiveness of student learning. ${ }^{26,27} \mathrm{E}$ learning is the term coined for the use of the computer and a network-enabled service to facilitate education. Skills and knowledge are conveyed in interesting and interactive forms, such as video, text, images, and more to encourage learning and expand knowledge. ${ }^{28}$

The computer revolution has also included the integration of computerised assessment tools, also referred to as computer-based assessments or e-assessments. These use a desktop computer, or its equivalent, to record, administer, and mark examinations, and to provide feedback to students for formative and summative purposes. ${ }^{29}$ Technology allows the testing of knowledge via automated multiple-choice questions, audio-visual content, and online quizzes. In the UK, the Computer-Assisted Assessment (CAA) Centre has reported that these e-assessment practices have made a significant contribution to higher education. ${ }^{16}$ The CAA has described several benefits of using an electronic mode of assessment. These include improved learning, facilitated assessment over a broad range of topics, timely feedback to students, improved objectivity and consistency, and reduced administrative workload. These perceived advantages may explain why electronic assessments have been utilised in many educational settings, and may account for the increasing preference for the utilisation of computerised tools over traditional paper and pen systems. ${ }^{30}$ Furthermore, in the US, the implementation of electronic methods of assessment in educational institutions has been driven by social policy. This policy requires educational institutions to provide equal learning opportunities for students with special learning needs. ${ }^{14}$ The introduction of the Disability Discrimination Act (1995) and the Special Educational Needs and Disability Act (SENDA), (2001), resulted in any act of discrimination in educational provision and related services being declared unlawful. ${ }^{14}$ Thus, more educational institutions are seeking computerised and digitised technology options that cater for the range of students' needs.

Computers and other electronic devices have been used in the administration and scoring of practical skills examinations, such as OSCEs. The term eOSCE has been used to reflect these electronic assessment methods. ${ }^{14}$ The utilisation of eOSCEs has introduced adaptations into the examination of practical skills: computers and other electronic devices are used to deliver examinations and evaluate the competency of students with or without the presence of an examiner. This review now presents examples of reports in which computers and other electronic devices were used to administer and score an eOSCE.

\section{Computers in eOSCEs}

Desktop computers have been used to administer a form of eOSCE. Nackman et al employed a web-based, multi-station eOSCE to assess their students in a surgical course. ${ }^{15}$ Previous case study information and paper OSCE items were transformed into an electronic document and converted into narratives and quizzes. The students could then access this document online using the internet. As students completed each item, software captured their responses and generated a score for each station. The authors reported that the web-based eOSCE method was less laborious to administer, reducing both the academic workload during delivery and the scoring of the examination. Importantly, when compared to their traditional paperbased OSCE, the results of the web-based OSCE showed no statistically significant differences in student scores. ${ }^{15}$ Therefore, the desktop computer-based eOSCE may be considered as potentially equivalent to the traditional format in terms of rating student performance. Holyfield et al also administered a desktop computer-based eOSCE to dentistry students and reported similar findings. ${ }^{12}$ Each dentistry student was assigned a computer station where they sat and answered questions related to various scenarios. The researchers in this study reported that this eOSCE format was less chaotic than previous examinations, and the students appeared to be more relaxed when compared with their traditional OSCE. Additionally, by using the eOSCE, all students were examined simultaneously in one session rather than the multiple sessions previously required with the traditional OSCE. Consequently, the number of staff members required to administer the examination was greatly reduced..$^{12}$ Examining 
students practical skills via a desktop computer-based examination is somewhat different to the assessment of the actual performance of practical skills; however, both groups of authors reported that the computerised "mock" scenarios in their eOSCEs were effective in achieving learning outcomes. ${ }^{12,15}$

Another study conducted by Palarm et al investigated the use of a desktop computer-based eOSCE in evaluating the skills of students studying diagnostic imaging. ${ }^{14}$ Each student sat at a computer station with a CD-ROM containing the examination. In addition to the advantages cited by the other authors who used a desktop computer-based eOSCE, the investigators in this study reported that using the CD-ROM ensured optimal picture quality and continuity of the examination without having to depend on servers to download images and information. Paper formats were simultaneously available to the students, which they considered beneficial because they could use the computer version to analyse images while using the paper version to view corresponding text. The format of the eOSCE was perceived as being close to "real-world" experiences by students. For students studying diagnostic imaging, this form of computerised assessment was very similar to the practical skills that they must demonstrate in the workplace, so the desktop computer-based eOSCE was closely related to the practical skills that would be performed in the clinical setting. This made the eOSCE more realistic than the conventional OSCE for these students. This format appeared to promote student autonomy during the examination process and diminished students' anxiety and stress. ${ }^{14}$

Several other studies have reported the administration of computerised versions of various types of assessments involving varied student skills, all of which have reported similar advantages to traditional methods. ${ }^{16,22,27}$ In each of these studies, the students did not perform practical skills in the traditional sense of the OSCE; it was their competency in skills knowledge which was evaluated. These studies provide examples of how the OSCE has been modified from its original concept into eOSCEs that utilise available technologies. Though these studies reported positive learning outcomes, it should be noted that the desktop computer-based eOSCE format does not require students to physically perform a practical skill, so it might be viewed as inferior to traditional methods.

\section{Use of PDAs and Hand-Held Devices in Education}

In the past 10 years, the use of mobile devices has risen significantly and even surpassed that of PC usage with sales reported at greater than $50 \%$ more for mobile devices than for the common PC. ${ }^{31}$ This increase has greatly been influenced by the prevailing social trends with more and more individuals using mobile devices to increase efficiency, organise daily activities, enhance communication, and build knowledge. ${ }^{32}$ Thus, the use of mobile devices has been embraced by, and incorporated into, a diverse range of industries including the education sector. ${ }^{30}$ The range of devices includes tablet PCs, PDAs, smartphones, iPods, iPads, and many more. The use of handheld computing systems commonly referred to as PDAs has also gained popularity within the healthcare industry. ${ }^{32-34}$ The use of PDAs is reported to have improved patient care and the quality of medical practice in general, as the PDA can provide clinicians with rapid access to clinical information, patients' data and tests results, and provide other clinical support. ${ }^{35}$

The steady rise in the use of mobile devices in the health care professions has paved the way for their use in health education, and more recently other areas of education. Mobile devices have become an integral tool in the learning process for many students. Their use in this context has been termed mobile or m-learning. ${ }^{36}$ Increasingly, institutions of higher education are incorporating mobile wireless technology into their curricula design, because mobile technology offers flexible educational options such as distance learning. With information available anytime and anywhere, students can retrieve lecture material offsite, keep track of class assessments and evaluations, and participate in group discussions, all of which are reported to improve the student learning experience along with the efficiency and effectiveness of teaching. 37,38

\section{PDAs and Hand-Held Devices in eOSCEs}

The transition to using PDAs and other mobile devices in education has included the evaluation of skills assessments. Incorporation of mobile devices in the administration of practical skills assessment like the OSCE has coined the term mobile OSCE or m-OSCE. ${ }^{39}$ In these instances, two formats have been developed. In the student-based format, students are provided with a mobile device uploaded with a compatible version of an eOSCE and they complete an examination. In the second format, the mobile devices are used exclusively by examiners, who are provided with a mobile device uploaded with a checklist which they use to score students' performance of practical skills. This second format, which more closely reflects the conventional OSCE format, was the more common method reported in the literature for skills assessment.

Using a mobile device to upload student scores during practical examinations was preferred by assessors because it greatly reduced administrative time. Mobile device usage in eOSCEs was reported to greatly improve the timeliness of data gathering and entry. ${ }^{23,32}$ One study compared the time required to prepare and generate results in practical examinations and found that using the traditional paper-based OSCE format took 525 minutes, but when PDAs were utilised, this time was reduced to 120 
minutes in its first year of instalment, and further reduced to 35 minutes in subsequent years. ${ }^{21}$ User satisfaction was correlated with the reduction in administrative time and was one of the major factors that made PDA use an attractive alternative in eOSCEs. These electronic devices were reported to also improve the efficiency of the marking process with preloaded feedback statements making evaluation easier and more rapid. Another study reported that automatically generated feedback sent immediately after the examination increased student satisfaction with the examination process. ${ }^{19}$ The flexibility of the software used with the PDAs allowed examiners to perform several tasks simultaneously during the eOSCE and resulted in the Medical Education Unit of the University of Vienna replacing paper and pen OSCEs with one administered via a handheld computer. ${ }^{19}$ Schmidts noted that in addition to the evaluation of students' performance and automated feedback, examiners also entered suggestions for new examination items as the examination progressed. ${ }^{19}$ Since all entries were synchronised and submitted electronically, this created a bank of questions that could be used in future assessments.

Furthermore, the utilisation of mobile devices for assessing students in practical examinations was reportedly more effective because of the increased accuracy in scoring and grading. 21,40 Data on student performance are digitally collected at the point of entry, overcoming issues that occur in traditional paper-based OSCEs, such as illegible handwriting and errors encountered during the transfer of data from paper to computer. Moreover, the use of this technology was reported to result in a relatively low occurrence of missing or lost data in comparison to the traditional paper and pen method. ${ }^{30,41}$ Additionally, since all data are stored in a remote database, subsequent statistical evaluations can be conducted, for example, identifying the most frequent mistakes students make during practical assessments. This information can then be used to help improve students' skills and learning. ${ }^{19,21,23}$

In relation to giving student feedback, eOSCEs were favoured over traditional methods not only because students received automated feedback in a timely manner, but also because the use of this technology was believed to improve the quality of the feedback. ${ }^{19,21}$ Schmidts reported that in a formative OSCE administered to medical students, the examiners were specifically asked to only record the wrong or incomplete actions they observed students perform. ${ }^{19} \mathrm{As}$ the examiner observed a task and an incorrect procedure was noted, they could select the task which opened a checklist of options from which they could select a corresponding action. If a more generalised action, such as a "vein puncture" was observed for example, a pop-up list consisting of more detailed preloaded statements pertaining to vein puncture would open, and the examiner specifically recorded the action that was incorrectly performed, for example "site contaminated." Once the examination was completed, all the data were synchronised and transferred to a desktop computer. This automated process compiled the results to generate comprehensive feedback. Since the feedback identified only incorrect actions, students could specifically pinpoint incorrect skills and focus on those areas for improvement. Though the students perceived this as helpful in identifying incorrect performance, feedback relative to correct performance can also be provided through eOSCEs. Students can store and easily retrieve the feedback given to them from previous assessments to help guide their learning. ${ }^{20}$ In some cases, in addition to a checklist of actions or feedback statements, feedback can also be provided via free-text comments, an option which was reported to enhance feedback. ${ }^{21}$

The portability and flexibility of mobile devices is a major contributing factor to their preferred use over conventional paper and pen or desktop or laptop computers. Hand-held devices facilitate mobility for their users and can therefore be used in varying environments, such as in fieldwork, to rapidly collect and instantly enter data at the point of collection where other formats are unsuitable.42-44 In eOSCEs, portable devices are considered ideal because they allowed versatility. Examiners can move around from station to station and observe students while simultaneously scoring and entering data on their performance. ${ }^{21}$

Portable electronic devices have been used in diverse situations in OSCEs. Not only are they used as tools for examiners to record assessments of performance, but also as tools to assist students with a disability. Recently, the University of Ottawa used the iPod Touch as a tool to administer an eOSCE to dyslexic students. ${ }^{45}$ The examination text was converted into an oral format so the students could simultaneously hear and read the examination questions as they progressed through the OSCE stations. This technology assisted those students with learning disabilities perform as competently as their counterparts during clinical examinations.

One important aspect of OSCEs is the evaluation of communication skills. Effective communication is essential in clinical practice, and students with limited language proficiency have been shown to perform more poorly in communication stations thereby hindering their success. ${ }^{46}$ Most institutions today have an international student body, and it is important to attract cohorts from diverse backgrounds to professional programs. However, it can be challenging to provide equal opportunities for students who do not speak the native language of the country, or in countries where there is more than one national language. E-OSCEs can be formatted to circumvent this language barrier thereby promoting equity. Suitable software can be used to create a bank of questions in different languages to cater to the language range represented in the study cohort. The Faculty of Medicine at the University of Ottawa in Canada has trialled this approach to eliminate language bias for medical students in their bilingual 
university. In this trial, students used an iPad to access their station-based gross anatomy examination. They were able to choose the language they were most comfortable using and proceed to answer the multiple choice questions as they rotated from station to station. ${ }^{47}$ However, the current review was not able to identify any studies that used multiple languages to provide student feedback from practical skills examinations.

The transition from traditional paper-based OSCE formats to electronic formats has also been reported to be highly costeffective. One report estimated their annual savings at $\$ 150,000$ after converting from paper-based examinations to using a PDA.48 An eOSCE can save administrators time in creating and organising the examination. ${ }^{19,20}$ When an eOSCE is studentdirected, fewer examiners are required, as the responses are collected electronically and the generation of feedback is automated. The use of eOSCEs also results in less paperwork for both students and administrators. ${ }^{19,20}$ Overall, eOSCEs administered via mobile devices were preferred by examiners because they were relatively easy to use and greatly reduced administrative time. E-OSCEs required minimal training and were considered to be less intrusive and stressful to the students compared to the use of paper checklists. ${ }^{19,20}$

\section{Other Technologies}

Another technology that has been used in evaluation of clinical skills competency, albeit with lesser frequency, is videorecording, also known as video OSCE or VOSCE. Video recorders have been used to film students as they perform tasks across a circuit of stations, and then an examiner subsequently assesses the student at a later time from the video. ${ }^{17,18}$ Although good inter-rater reliability has been reported using this method, the scores on videotaped observations were consistently lower than those of real-time observations. Two studies that report using this method have suggested that the scoring may not have been equivalent as a result of factors such as lack of training for the examiners of the videos, differences in the expertise of the examiners, differences in direct versus video observation, and possible examiner bias. ${ }^{6,17}$ Alternatively, examiners may not have been able to observe all angles of student performance, or explore possible additional student knowledge through specific questioning when performance was poor.

Digital pen and paper is another technology that has been used as a substitute for the traditional paper-based OSCE. ${ }^{49}$ This technology utilises special patterned paper and a digital pen, which houses a small camera and Bluetooth transceiver. For the examiner, the pen feels like a normal ball-point pen and also houses the normal ink cartridge, so they can write on the pattern paper as they would normally. The pen takes rapid digital snapshots which are converted into an image representing the scoring and student feedback. This method collects the information at the time it is recorded, thereby allowing the rapid conversion of the data into usable digital forms. In eOSCEs using digital pen technology, an examiner scores on a checklist printed on the special paper as well as providing written comments. Once the examiner has completed the checklist and comments, they select a "send option" and the written information is then uploaded electronically to a remote computer system, and selected handwriting instantly becomes text entries. This technology was reported to have several benefits, including low cost compared to laptops and tablets; minimal user training required; data immediately available for analyses; and student feedback and examiners able to receive feedback on their marking for quality assurance purposes. The input from an examiner is additionally checked for accuracy as the pen notifies the users if the patterns are not recognised. At the end of each checklist, the user has to authorise data transfer to the server, a process that verifies data transmission and prevents loss. Additionally, individual details are recorded simultaneously, thereby providing duplicate copies without added labour.50 The authors reported several difficulties when initially implementing this system, including difficulties linking examiner marks to the correct student and communication problems using the Bluetooth. These were resolved by the third trial of the system by using unique patterned paper to identify each student and a pen holder which quickly transmitted the data between consecutive students.

\section{Limitations of Electronic Testing}

Although the use of electronic devices in practical assessment has overall been reported to be successful, there are limitations. Despite several studies reporting that it improved cost effectiveness, one commonly identified disadvantage of this testing format is the greater demand for resources and the overall costs of the entire scheme. ${ }^{51,52}$ Costs related to the initial design and development of the exam format, as well as finding software suitable for the particular assessment items, can be expensive. Where an external provider is used, the set-up prices are expensive depending on the specificity required and the on-going contract requirements. In some instances, specialised computer and IT experts are required to amend and maintain the software, and on-site technical support to rapidly troubleshoot problems during the examinations is also required, resulting in immense technology costs. ${ }^{51,52}$

The process of creating the online test questions and answers can also be time consuming. ${ }^{45}$ Furthermore, the conversion of paper items into a format suitable for the particular software is not always possible. Dearnley et al found it difficult to replicate their existing paper-items into PDA format since the latter did not support many of the same features. ${ }^{22}$ Once the conversion 
process is achieved, extensive trials must be carried out to ascertain the functionality of the entire system, and these can be costly and time consuming. Costs may also be associated with on-going updating and maintenance of the databases where data are stored as well as accessing the data. ${ }^{23}$ Where hand-held devices are utilised, there is the risk of theft as, these devices are pocket size and portable. ${ }^{22}$ Taken together, these reasons can greatly limit the use of electronic devices where adequate funding is not available to support these costs.

Unlike paper-based assessments that require limited training for examiners' use, the end users of electronic-based assessments require training and professional instruction of both the usage of the device and the examination system in order to ensure seamless integration of the technology during the examination session. However, this was usually only considered a concern in the initial set-up process and was expected to improve with increased familiarity of the system. ${ }^{20}$ Cultural acceptability of the use of mobile devices as modes of assessment among assessors and students is also a challenge. ${ }^{22}$ In some instances, the use of mobile devices in education and assessment may be limited by the prevailing socio-cultural trend. In a case study conducted by Dearnley et al, dietetic and physiotherapy students reported that in some environments (clinical rotations), they were not allowed to use, or were discouraged from utilising, mobile devices. ${ }^{22}$ Results of the same case study found that students did not feel the learning experience was beneficial when they were assessed by a lecturer who they perceived as technologically incompetent. ${ }^{22}$ Educators may also see the introduction of new technology and methodologies as a daunting and unnecessary task. They have to learn new skills and incorporate these into their curricula, and not all educators embrace new technologies. While some users may be optimistic about using new technology despite their lack of familiarity, others may not be as enthusiastic about the transition, and therefore not favour its use.

In any examination setting, effective management of the examination environment and process is also crucial in order to ascertain smooth running of the examination. Using technology always poses the risk of technological mishaps and equipment malfunction. The possibility of data and information loss if servers and internet connections lose functionality can also be disadvantageous. ${ }^{45}$ Constant backup is therefore required to ensure that data is not lost in the event of a technological mishap. There may also be a need for additional staff to manage data once it is entered, to coordinate the uploading of data, and to provide troubleshooting support. This support is usually important in the initial stages, but may be unnecessary as the technological processes became more familiar and better refined. Where hand-held devices were used by students in eOSCEs to assist students with a disability in reading the examination questions, concerns existed about using a new system especially if it has not been trialled previously. ${ }^{45}$ Students using iPods or iPads in clinical eOSCEs were concerned with the overall functionality of the devices. They were anxious about the devices stopping or freezing during the examination. Moreover, students reported that it was challenging to handle both the device and other examination-related equipment. These additional concerns during an already stressful examination situation can cause further student anxiety and stress, and extra time may be needed during examination sessions. Therefore, users have to be constantly assured about functionality prior to the examination sessions, plus a back-up plan must be in place ready to be implemented if necessary.

Although the use of computer-based assessment is increasing and in some sectors replacing traditional formats, there are concerns about the accuracy of examiner scoring during electronic examinations. Student results obtained from electronic versions of examinations are not always the same as traditional formats, even when identical examinations in each format are administered. ${ }^{53}$ Generally, scores obtained from paper formats are found to be higher than those administered via computers or their equivalent, although the differences between the scores are reported as small or negligible. A review examining education measurement approaches reports the results of 23 studies that evaluated the differences in examiner scores between computerised and paper-based formats of the same examination. This review found that three studies reported a higher score in the computerised format, nine reported a higher score in the paper-based format and 11 reported no difference between the two formats. ${ }^{54}$ This difference in scoring has been termed the test-mode effect, and it is theorised that the reasons for the computerised assessment scores being lower may be individual learner differences, content familiarity, and computer knowledge. ${ }^{53}$

Although a perceived advantage of using mobile handheld devices during practical skills assessment is their light weight and small size making portability and mobility easy, their small size negatively affects other aspects of the examination format. Kneebone et al reported the size of the PDA screen in their examination was a limitation, as it restricted how much information could be presented in one field of view. ${ }^{20}$ This feature should be considered in the choice of devices to be utilized and in the design of the software used to create the examiner's interface in order to make the device user-friendly. To compensate for the size of the PDA screen, Kneebone et al suggested providing a paper version of the examination to examiners that they can refer to until they became familiar with the interface and software. ${ }^{20}$ However, this adds an additional level of complexity to the administration of the eOSCE. Another limitation of administering eOSCEs relates to the nature of the examination setting. If an eOSCE is administered via a desktop computer with only mock scenarios used, students are not required to physically perform

(C) The Internet Journal of Allied Health Sciences and Practice, 2014 
tasks. All aspects of the examination are presented electronically, so there is no use of props, models, and live persons to create an appropriate practical scenario. One group of authors that used desktop computers for an eOSCE agreed that this technology did not allow the use of standardised patients to test students' interpersonal or communication skills. ${ }^{12}$ To overcome these shortcomings, video recordings of patients would have to be provided and the students asked to address particular issues following viewing of the video.

\section{CONCLUSION}

In the education sector, the transition from traditional paper-based to computerised assessment is steadily growing, and examples of electronically administered practical skills assessments are beginning to emerge. Computerised assessment encompasses administration and marking, as well as providing student feedback through web-enabled technologies. In particular, the use of mobile devices has been favoured over desktop computers for practical skills assessments, or eOSCEs. Mobile devices are reported to be user friendly, accessible and time efficient when used as tools for student assessment. eOSCEs have also been reported to reduce staffing costs, minimise scoring and data entry errors, provide students with prompt feedback and provide academics with automated storage of examination data. Thus, while eOSCEs have been associated with technological challenges and require initial financial investment, the benefits of using mobile technology in the assessment of pre-professional clinical skills outweigh the limitations.

\section{ACKNOWLEDGEMENT}

Support for this publication has been provided by the Australian Government Office for Learning and Teaching (Grant Ref.: PP10-1628). The views expressed in this publication/activity do not necessarily reflect the views of the Australian Government Office for Learning and Teaching.

\section{REFERENCES}

1. Boud D, Falchikov N. Aligning assessment with long-term learning. Assessment \& Evaluation in Higher Education. 2006;31:399-413.

2. Rushforth $\mathrm{H}$. Objective structured clinical examination (OSCE): Review of literature and implications for nursing education. Nurse Education Today. 2007;27(5):481-90. [PMID 17070622]

3. Harden R, Stevenson M, Downie WW, Wilson GM. Assessment of clinical competence using objective structured examination. Br Med J. 1975;1(5955):447-51. [PMID 1115966]

4. Harden RM, Gleeson FA. Assessment of clinical competence using an objective structured clinical examination (OSCE). Med Educ. Jan 1979;13(1):41-54. [PMID 763183]

5. Ross M, Carroll G, Knight J, Chamberlain M, Fothergill-Bourbonnais F, Linton J. Using the OSCE to measure clinical skills performance in nursing. J Adv Nurs. 1988;13(1):45-56. [PMID 3372885]

6. Sturpe DA. Objective structured clinical examinations in doctor of pharmacy programs in the United States. Am J Pharm Educ. 2010;74(8):148. [PMID 21179256]

7. Mcllroy JH. The impact of an alternative approach to computing station cut scores in an OSCE. Acad Med. Oct 2000;75(10 Suppl):S18-20. [PMID 11031162]

8. Fields HW, Rowland ML, Vig KW, Huja SS. Objective structured clinical examination use in advanced orthodontic dental education. Am J Orthod Dentofacial Orthop. May 2007;131(5):656-63. [PMID 17482087]

9. van den Berk IA, van de Ridder JM, van Schaik JP. Radiology as part of an objective structured clinical examination on clinical skills. Eur J Radiol. Jun 2011;78(3):363-7. doi: 10.1016/j.ejrad.2008.10.042. [PMID 19091506]

10. Hawker JA, Walker KZ, Barrington V, Andrianopoulos N. Measuring the success of an objective structured clinical examination for dietetic students. J Hum Nutr Diet. Jun 2010; 23(3):212-6. doi: 10.1111/j.1365-277X.2010.01050.x. [PMID 20337849]

11. Turner JL, Dankoski ME. Objective structured clinical exams: a critical review. Fam Med. Sep 2008; 40(8):574-8. [PMID 18988044]

12. Holyfield LJ, Bolin KA, Rankin KV, Shulman JD, Jones DL, DeSpain Eden B. Use of computer technology to modify objective structured clinical examinations. J Dent Educ. 2005;69(10):1133-6. [PMID 16204679]

13. Campbell A. Digital forms of assessment: Assessing what counts, the performance. Paper presented at: Curriculum, technology \& transformation for an unknown future. Proceedings ascilite Sydney 20102010.

14. Palarm TW, Griffiths M, Phillips R. The design, implementation and evaluation of electronic objective structured clinical examinations in diagnostic imaging: an 'action research' strategy. Journal of Diagnostic Radiography and Imaging. 2004;5(2):79-87.

15. Nackman GB, Griggs M, Galt J. Implementation of a novel web-based objective structured clinical evaluation. Surgery. 2006;140(2):206-11. [PMID 16904971] 
16. Crisp GT. Raising the profile of diagnostic, formative and summative e-assessments. Providing e-assessment design principles and disciplinary examples for higher education academic staff. Strawberry Hills, NSW: Australian Learning \& Teaching Council Ltd; 6 September 2010, 2008.

17. Vivekananda-Schmidt $P$, Lewis $M$, Coady $D$, et al. Exploring the use of videotaped objective structured clinical examination in the assessment of joint examination skills of medical students. Arthritis Rheum. 2007;57(5):869-76. [PMID 17530689]

18. Sturpe DA, Huynh D, Haines ST. Scoring objective structured clinical examinations using video monitors or video recordings. Am J Pharm Educ. 2010;74(3):44. [PMID 20498737]

19. Schmidts MB. OSCE logistics - handheld computers replace checklists and provide automated feedback, Objective structrures clinical exam. Med Educ. 2000;34(11):947-58. [PMID 11107035]

20. Kneebone R, Nestel D, Ratnasothy J, Kidd J, Darzi A. The use of handheld computers in scenario-based procedural assessments. Med Teach. Nov 2003;25(6):632-42. [PMID 15369912]

21. Treadwell I. The usability of personal digital assistants (PDAs) for assessment of practical performance. Med Educ. Sep 2006;40(9):855-61. [PMID 16925635]

22. Dearnley C, Taylor J, Hennessy S, et al. Using Mobile Technologies for Assessment and Learning in Practice Settings: Outcomes of Five Case Studies. International Journal on E-Learning. 2009;8(2):193-207.

23. Torre DM, Treat R, Durning S, Elnicki DM. Comparing PDA- and paper-based evaluation of the clinical skills of third-year students. WMJ. Feb 2011;110(1):9-13. [PMID 21473507]

24. van Hell EA, Kuks JB, Dekker MJ, Borleffs JC, Cohen-Schotanus J. The digital pen as a novel device to facilitate the feedback process. Med Teach. 2011;33(6):497-9. doi: 10.3109/0142159X.2010.540271. [PMID 21355702]

25. Yamaguchi S, Yoshida D, Kenmotsu H, et al. Objective assessment of laparoscopic suturing skills using a motion-tracking system. Surg Endosc. Mar 2011;25(3):771-5. doi: 10.1007/s00464-010-1251-3. [PMID 21072671]

26. Shortis M, Burrows S. A review of the status of online, semi-automated marking and feedback systems. ATN Assessment Conference, RMIT University. 2009:1-11.

27. Segall N, Doolen TL, Porter JD. A usability comparison of PDA-based quizzes and paper-and-pencil quizzes. Computers \& Education. 2005;45:417-32.

28. Pinto A, Selvaggi S, Sicignano G, et al. E-learning tools for education: regulatory aspects, current applications in radiology and future prospects. Radiol Med. Feb 2008;113(1):144-57. doi: 10.1007/s11547-008-0227-z. [PMID 18338134]

29. Cantillon P, Irish B, Sales D. Using computers for assessment in medicine. British Medical Journal. 2004;329(7466):606-9. [PMID 15361445]

30. Palen LA, Graham JW, Smith EA, Caldwell LL, Mathews C, Flisher AJ. Rates of Missing Responses in Personal Digital Assistant (PDA) Versus Paper Assessments. Eval Rev. 2008;32(3):257-72. doi: 10.1177/0193841X07307829. [PMID 18456877]

31. Blayney M. Mobile device sales to trump PC sales in 2011. Smarter business ideas2011.

32. Torre DM, Wright SM. Clinical and educational uses of handheld computers. South Med J. Oct 2003; 96(10):996-9. [PMID $14570344]$

33. Lu YC, Xiao Y, Sears A, Jacko JA. A review and a framework of handheld computer adoption in healthcare. Int J Med Inform. 2005;74(5):409-22. [PMID 15893264]

34. Wegis $\mathrm{H}$, van der Mars $\mathrm{H}$. Integrating Assessment and Instruction: Easing the Process with PDAs. Journal of Physical Education, Recreation and Dance. 2006;77(1):27-34.

35. Baumgart DC. Personal digital assistants in health care: experienced clinicians in the palm of your hand? The Lancet. 2005;366(9492):1210-22. [PMID 16198770]

36. Herrington J, Herrington T, Ferry B, Olney I, Mantei J. Using mobile technologies to develop new ways of teaching and learning. 2009; http://ro.uow.edu.au/edupapers/75. Accessed 15th September 2013.

37. Kim SH, Mims C, Holmes KP. An introdution to current trends and benefits of mobile wireless technology use in higher education. Association for the Advancement of Computing in Education Journal. 2006;44:77-100.

38. Jansen W, Ayers R. An overview and analysis of PDA forensic tools. Digital Investigation. 2005;2:120-32.

39. Belouin P. A simple and mobile solution for marking your OSCE exam. 2009; http://www.moscee.com/. Accessed 12th Oct, 2011.

40. Yuen SC-Y, Yuen PK. PDAs as educational power tools. Tech Directions. 2003;62(9):14.

41. Seebregts CJ, Zwarenstein M, Mathews C, et al. Handheld computers for survey and trial data collection in resource-poor settings: Development and evaluation of PDACT, a Palm ${ }^{\text {TM }}$ Pilot interviewing system. Int J Med Inform. 2009;78(11):721-31. doi: 10.1016/j.jijmedinf.2008.10.006. [PMID 19157967]

42. Fletcher LA, Erickson DJ, Toomey TL, Wagenaar AC. Handheld computers: A feasible alternative to paper forms for field data collections. Eval Rev. 2003;27(2):165-78. [PMID 12703341]

43. Missinou MA, Olola CH, Issifou S, et al. Short report: Piloting paperless data entry for clinical research in Africa. Am J Trop Med Hyg. 2005;72(3):301-3. [PMID 15772326] 
44. Dale O, Hagen KB. Despite technical problems personal digital assistants outperform pen and paper when collecting patient diary data. J Clin Epidemiol. Jan 2007;60(1):8-17. [PMID 17161749]

45. Renaud G, Jalali A. Helping dyslexic medical students pass their OSCE exams. elearn magazine: ACM; 2011:1-3.

46. Haq I, Higham J, Morris R, Dacre J. Effect of ethnicity and gender on performance in undergraduate medical examinations. Med Educ. 2005;39(11):1126-8. [PMID 16262808]

47. Jalali A, Trottier D, Tremblay M, Hincke M. Administering a gross anatomy exam using mobile technology. elearn Magazine: ACM. 2011:1-3.

48. Briggs B. Pushing data out to PDAs. Health Data Manag. Jul 2002;10(7):28-30. [PMID 12141051]

49. Despont-Gros C, Landau R, Rutschmann O, Simon J, Lovis C. The digital pen and paper. Evaluation and acceptance of a new data acquisition device in clinical settings. Methods of information in medicine. 2005;44(3):359-68. [PMID 16113758]

50. van Hell EA, Kuks JBM, Dekker MJ, Borleffs JCC, Cohen-Schotanus J. The digital pen as a novel device to facilitate the feedback process: Faculty of Medicine, 2009.

51. Meissner D. A successful conversion: The benefits and best practices of computer-based testing. 2007; http://www.prometric.com/NR/rdonlyres/eedfjprgpphggzks55357w7wpms7tanhhb2ifyyzd7ukicuayun7xoulr6yiqne75abm3y2 3p6ib2v4s3esasih4wvf/ConversionBenefitsBestPractices.pdf. Accessed 27th July, 2011.

52. Professional Testing Inc. Converting to computer-based testing. 2006; http://www.proftesting.com/test_topics/pdfs/cbt.pdf. Accessed 15th September, 2013.

53. Clariana R, Wallace P. Paper-based versus computer-based assessment: key factors associated with the test mode effect. British Journal of Educational Technology. 2002;33(5):593-602.

54. Bunderson CV, Inouye DK, Olsen JB. The four generations of computerized educational measurement. In: Linn RL, ed. Educational Measurement. Washington, DC: American Council on Education; 1989:367-407.

\section{KEY TERMS}

Objective Structured Clinical Examinations (OSCEs), eOSCE, Computerised Assessment, Clinical Skills, Student Feedback, iPad 